\title{
PROPOLİSİN GENEL ÖZELLİKLERİ VE KULLANIMI
}

\author{
Merve Aydın*, Derya Arslan, Selman Türker \\ Necmettin Erbakan Üniversitesi, Mühendislik ve Mimarlık Fakültesi, Gıda Mühendisliği Bölümü, Konya, Türkiye
}

Geliş / Received: 26.08.2020; Kabul / Accepted: 19.12.2020; Online bask1 / Published online: 28.12.2021

Aydın, M., Arslan, D., Türker, S. (2021). Propolisin genel özellikleri ve kullanımı. GIDA (2021) 46 (1) 69-81 doi: $10.15237 /$ gida. GD20102.

Aydn, M., Arslan, D., Türker, S. (2021). General features of propolis and its use. GIDA (2021) 46 (1) 69-81 doi: $10.15237 /$ gida. GD20102.

ÖZ

Günümüzde fonksiyonel doğal ürünlerin popülerliğinin artmasıyla bilim adamlanı, propolisi daha yakından incelemeye ve sağlıktan gidaya, gıdadan kozmetiğe birçok üründe kullanmaya başlamıştr. Ham propolis, arılar (Apis mellifera) tarafindan bitkilerden toplanarak elde edilen, kovanda dezenfektan, yapı ve savunma maddesi olarak kullanılan, reçinemsi bir üründür. Yapısındaki biyoaktif bileşiklerden dolayı antienflamatuvar, antioksidan ve antibakteriyel gibi etkiler gösterir. Ham propolisin güçlü aroması, yapışkanlığ1 ve sudaki çözünürlüğünün az olması birçok alanda kullanımını kısıtlar. Ekstraksiyon yöntemiyle elde edilen propolisin etken maddeleri; saf halde takviye edici gıda olarak kullanımın yanında çeşitli gıdaların fonksiyonel değerini artırmada da kullanılmaktadır. Bu derlemede; ham propolisin çözünürlügünü ve biyoyararlllı̆̆ını artıran son işleme teknikleri, propolis ekstraktının gıda alanında kullanımı ve güvenli tüketim miktarları yer almaktadır. Anahtar kelimeler: Propolis, biyoaktif madde, fenolik madde, antioksidan, antibakteriyel, ekstraksiyon, takviye edici g1da

\section{GENERAL FEATURES OF PROPOLIS AND ITS USE}

\begin{abstract}
Nowadays, with the increasing popularity of functional natural products, scientists have begun to study propolis in more detail and use it in many products from health to food, from food to cosmetics. The raw propolis is a resin-like product used as a disinfectant, structure, and defense agent in the hive, collected by bees (Apis mellifera) from plants. Propolis demonstrates anti-inflammatory, antioxidant, and antibacterial effects due to the bioactive compounds it contains. The strong aroma, stickiness, and low water solubility of the raw propolis limit its use in many fields. The active ingredients of propolis obtained by extraction method are used as food supplement in pure form, as well as to increase functional value of various foods. In this review includes novel processing techniques that increase the solubility and bioavailability of raw propolis, the use of propolis extract in the food field, and its safe levels of intake.
\end{abstract}

Keywords: Propolis, bioactive substance, phenolic substance, antioxidant, antibacterial, extraction, food supplement

\footnotetext{
${ }^{*}$ Yazışmalardan sorumlu yazar /Corresponding author:

(1):merveeydn@hotmail.com 0 (332) 3252024 (40 00)

国: 0 (332) 5820450

Merve Aydın; ORCID No: 0000-0002-0626-9911

Derya Arslan; ORCID No: 0000-0002-6655-9312

Selman Türker; ORCID No: 0000-0003-1233-7906
} 


\section{GİRIŞ}

$\mathrm{Bal}$ arılar1 (Apis mellifera L.) besin gereksinimlerini karşılamak üzere çiçekli bitkilerden ve meyve ağaçlarından polen ve nektar toplayarak bitkilerin döllenmesini ve bitki popülasyonunun devamlilı̆ 1 sağlarlar ve ürün kalitesini artırırlar. Bal arılanı; bal, polen, ar1 sütü, propolis, an ekmeği, anı zehiri ve apilarnil gibi gıda, ilaç, kozmetik ve diğer bazı sanayilerde besinsel ve katma değeri yüksek olan ar1 ürünlerini üretirler (Tüzün ve Bilgili, 2013; Silici, 2019). Ham propolis, arılar tarafindan çeşitli bitkilerin reçinemsi maddelerinin ve salgılarının toplanıp, içerisine bir miktar bal mumu, polen ve enzimler katılarak kovanlarda depolanan, farklı renklere sahip, reçinemsi, yapışkan bir üründür (Sharaf ve El-Naggar, 2018). Ham propolis; sarıms1, yeşil ve koyu kahverengi gibi değişen rengi, kendine has kokusu ile kovanda oluşan çatlak ve açıklıkların kapatılması ile kovan yalıtımı ve sterilizasyonunun sağlanması gibi amaçlarla arılar tarafindan üretilir ve kullanılır (Pobiega vd., 2019). Dünya ölçeğinde en fazla ham propolis;
Çin, Rusya, Brezilya, Amerika Birleşik Devletleri (ABD), Avustralya ve Uruguay gibi ülkelerden toplanmaktadır. Son yillarda ülkemizde de ham propolisin eldesinde ve tüketiminde artşs gözlenmektedir (Toreti vd., 2013).

Propolisin kimyasal bileşimi, kullanımı için standardizasyonunu sınırlayan botanik kaynakları ve coğrafi kökenlerinden dolayı büyük değişkenlik göstermektedir (Wang vd., 2020). Propolisin genel bileşiminde; reçine (\%50-55), bitkisel bal mumu (\%20-35), uçucu yağlar (\%5-10), polen (\%2-5) ve diğer organik bileşikler (\%5-15) yer almaktadır. Fenolik asitler ve bunların esterleri, flavonoidler, terpenler, aromatik aldehitler, alkoller, yağ asitleri, stilbenler ve steroidler, aminoasitler, lignanlar ve şekerleri içeren farklı propolis türlerinde 300 'den fazla bileşiğin mevcut olduğu bildirilmiş olup Çizelge 1'de verilmiştir (Righi vd., 2013; Sforcin, 2016; Elnakady vd., 2017).

Çizelge 1. Propoliste bulunan başlica bileşikler (Toreti vd., 2013; Elnakady vd., 2017)

\begin{tabular}{llc}
\hline Bileşenler & Ana maddeler & Miktar (\%) \\
\hline \multirow{2}{*}{ Reçine } & Flavonoidler & \\
& Terpenler & $50-55$ \\
& Kumarinler & \\
& Fenolik asitler ve esterleri & \\
& Esterler & \\
Bal mumu ve yağ asitleri & Diğer asit ve türevleri & $20-35$ \\
& Steroidler & \\
Uçucu yağlar & & \\
& Uçucu bileşenler & $5-10$ \\
Polen & Proteinler & \\
& Serbest aminoasitler & $2-5$ \\
& Vitaminler & \\
& Eser elementler & \\
& Ketonlar & \\
& Laktonlar & $5-15$ \\
& Kinonlar & \\
& Steroidler & \\
& Şekerler & \\
& & \\
\hline
\end{tabular}


Propolisin içerdiği biyoaktif bileşenler sayesinde antibakteriyel, antifungal, antioksidan, antikanserojen, antidiyabetik, antitümör ve antienflamatuvar gibi etkileri yapılan çalışmalarla kanıtlanmıştır (Ecem-Bayram vd., 2018; Duran, 2019). Ham propolisin; reçineli, suda az çözünen, viskoz, yapışkan, güçlü tat ve koku gibi yapısal özelliklerinden dolayı biyoetkinliği kısıtlıdır ve böylece doğal haliyle tüketilememektedir (Keskin vd., 2018). Bu nedenle ancak ekstraksiyon işleminden sonra tüketime uygun hale gelebilmektedir (Devequi-Nunes vd., 2018). Günümüzde teknolojinin gelişimine paralel, ekstraksiyon yöntemlerinde de zenginleşme olmuştur. Böylece ekstraksiyonda kullanılan çözücü miktarı en aza indirilmiş ve ekstraksiyon verimi artırılmıştır. İlgili olarak geleneksel yöntemlere alternatif günümüzde yeşil ekstraksiyon yöntemleri (mikrodalga destekli ekstraksiyon, ultrason destekli ekstraksiyon, basınçlı ekstraksiyon, süperkritik siv1 ekstraksiyon, sonikasyon destekli sivi ekstraksiyon gibi) kullanılmaktadır (Zhang vd., 2018). Ayrica enkapsülasyon yöntemi ile propolisin kısitlı kullanımına imkân sağlanmaktadır (Keskin vd., 2018). Ham propolis, an kovanlarındaki yapısal ve işlevsel niteliklerinin dışında yukanda da ifade edildiği gibi terapötik özellikleri nedeniyle; tp, eczacillk, veteriner hekimlik, gida, tarım ve kozmetik gibi alanlarda da kullanılmaktadır (Keskin vd., 2019). EFSA (European Food Safety Authority) (2018), propolisin güvenilir ve toksik olmayan bir ürün olarak kullanımını uygun bulmuştur. Ancak popolisin bilinçsiz kullanımına dayalı olası sağlığa zararlı etkisini önleyebilmek için günlük kullanılabilecek maksimum doz konusunda yeni klinik çalışmaların yapılması gerekmektedir (Silici, 2019). Bu derleme kapsamında; ham propolisin çözünürlüğünü, biyoyararlılığını ve tüketimini artırmaya yönelik kullanılan yeni proseslere, propolis ekstraktının gıda alanında kullanımına ve güvenli tüketim miktarlarına yer verilmiştir.

\section{PROPOLİSINN EKSTRAKSIYYONU}

Ham propolisin reçineli, viskoz, yapışkan, suda az çözünen, keskin tat ve aromalı yapısı itibariyle tüketimi ve biyoetkinliği kisıtlıdır. Bu yüzden eczacılık ve gıda gibi sektörlerde kullanılabilmesi için mutlaka ekstrakte edilmesi gerekmektedir (Keskin vd., 2018). Propolisin ekstraksiyonu için yaygin olarak kullanılan solvent ekstraksiyonunda (Zhang vd., 2018) çözücü olarak genellikle etil alkol, propilen glikol, gliserol veya su (Keskin vd., 2018; Silici, 2019); ayrica metil alkol, etil eter, kloroform, bitkisel yağlar, diklorometan ve aseton da kullanılmaktadır (Martinotti ve Ranzato, 2015). Propolis ekstraksiyonu sonunda içerisindeki bal mumu vb. safsızlıklar süzülerek uzaklaştırılır ve propolise antioksidan ve antibakteriyel gibi özellikler kazandıran biyoaktif bileşenler ekstrakt içinde elde edilir (Mello vd., 2010). Propolis; suda çok az çözünür/hiç çözünmez, eter, kloroform, aseton ve diğer organik çözücülerde kısmen, etanol ve metanolde ise daha iyi çözünür (Fitzgerald ve Flood, 2006). Birçok çalışmada etanol, propolis ekstraksiyonu için en iyi çözücü olarak rapor edilse de propolisin etanolik ekstraktının güçlü reçinemsi tadı, yan etkileri ve bazı insanların alkole karşı intoleransının olması tüketimindeki kısıtlayıcı faktörlerdir. Böylelikle araştırmacılar yeni, uyumlu, daha sağlıklı ve doğal çözücü arayışında olmuşlardır (Keskin vd., 2018). Propolisin zeytinyağ 1 ekstraktının antioksidan, antiradikal ve antipretik etki gösterdiği ve alkolik ekstraksiyonlara karşı alternatif olabileceği belirlenmiştir (Baysa, 2018). Son zamanlarda, doğal derin ötektik çözücüler (Natural Deep Eutectic Solvent) düşük veya sıfır toksisite, yüksek biyobozunurluk ve biyouyumluluk, suda düşük çözünürlük, doğal veya sentetik kimyasalları çözebilme ve çevre dostu gibi özelliklerinden dolayı "yeşil çözücüler" olarak geleneksel çözücülere alternatif bir şekilde kullanılmaktadır (Liu vd., 2018; Trusheva vd., 2019). Etanol, glikol ve su ekstraktlarına yeşil alternatifler olarak doğal derin ötektik çözücülerin kullanılması, doğrudan tüketim için daha uygun bulunurken alkollü ekstraktlarla benzer bileşikler elde edilmiştir (Funari vd., 2019).

Yeni teknolojilerin gelişmesiyle birlikte ekstraksiyon yöntemlerinin kurgulanmasındaki anlayış şekli değişerek; mikrodalga destekli ekstraksiyon, basinçlı ekstraksiyon (veya hızlandırılmıss solvent ekstraksiyonu), süperkritik s1v1 ekstraksiyonu, ultrason destekli ekstraksiyon gibi bazı modern veya yeşil ekstraksiyon metotları 
uygulanmaya başlanmıștır (Pobiega vd., 2019; Oroian vd., 2020). İlgili olarak bu anlayış değişikliği beraberinde; kısa ekstraksiyon süresi, düşük organik çözücü tüketimi ve daha yüksek seçicilik gibi bazı avantajları getirmiştir (Dhanani vd., 2017). Ultrason destekli ekstraksiyon yönteminde, çeşitli frekanslarda üretilen ses dalgaları $(20-25 \mathrm{kHz})$ ekstrakte edilecek hücre üzerine gönderilerek akustik kavitasyon oluşturulmaktadır. $\mathrm{Bu}$ şekilde hücre yapısı bozulduktan sonra bileşenlerin açığa çıması sağlanarak ekstraksiyon hızlanmaktadır (Chemat vd., 2017). Mikrodalga destekli ekstraksiyonda, yüksek frekanslı elektromanyetik dalgalar (300$300000 \mathrm{MHz}$ ), uyguladığı elektrik alan şiddetinin sonucunda iyonik bileşenleri harekete geçirmektedir. İyonların hareketiyle matris içine çözücü geçişi artarak bileşenlerin ekstraksiyonu kolaylaşmaktadır (Rodriguez-Jasso vd., 2011). Propolisin süperkritik ekstraksiyonunda bir yardımcı çözücü kullanılmadan elde edilen verimin, geleneksel etanolik ekstraksiyon ile elde edilen verimden çok daha düşük düzeyde olduğu, çözücü olarak etanol eklenmesinin ise ekstraksiyon verimini önemli ölçüde artırdığ bildirilmiştir (Devequi-Nunes vd., 2018). Yeo vd. (2015), propolisin etanol ekstraksiyonunda $\mathrm{pH}$ ayarlamasinin ve ultrason uygulamanin ekstraksiyon süresini ve kullanilan etanol miktarını önemli ölçüde azalttığını tespit etmiştir. Kayabaş1 (2019), propolis ekstraksiyonunda maserasyon, mikrodalga destekli ekstraksiyon ve ultrason destekli ekstraksiyon yöntemlerini kullanarak aralarından en yüksek toplam flavonoid ve fenolik madde miktarının sirasıyla maserasyon ve ultrason destekli yöntemden sağlandığını bildirmiştir. Ayrıca mikrodalga ekstraksiyon yöntemiyle elde edilen ekstraktların DPPH (2,2-difenil-1-pikrilhidrazil) serbest radikal tutucu aktivite değerinin, maserasyon ve ultrason destekli yöntemlere göre daha yüksek olduğunu rapor etmiştir. Reis vd. (2019) benzer bir çalışmada, geleneksel ekstraksiyon yöntemi ile karşılaştırdığında, ultrason destekli ekstraksiyonun kırmızı propolis ekstraktının antioksidan ve sitotoksik aktivitesini artırdığını gözlemiştir. Oroian vd. (2020), propolisten fenolik bileşikleri elde etmede kullandığ 1 tekniklerden; ultrason destekli ekstraksiyonun, mikrodalga destekli ekstraksiyon ve maserasyondan daha yüksek verim sağladığını ortaya koymuştur. Propolis üzerine biyotransformasyon çalışmalarının yapıldığı da gözlenmiştir. Bazı araştricıların biyotransformasyon yoluyla propolisin fenolik bileşenlerini ve biyoaktivitesini incelediği belirlenmiştir (Gardana vd., 2012; Dündar, 2019). Biyotranformasyon esnasinda, mikroorganizmalar belirlenen bileşiğe etki ederek farklı bileşikler oluşturur veya hedef bileşiğin miktarını değiştirirler (Hegazy vd., 2015). Yıldırım vd. (2018), Lactobacillus plantarum suşlarının (10, 8014, ATCC) biyotransformasyon yoluyla propolisteki alerjen bileşenlerin miktarını azaltmasını amaçlamıştur. Lactobacillus plantarum ATCC® 8014 suşunun kafeik asit ve sinamik asit esterleri dışındaki fenolik bileşiklerin miktarının azaltılmasında daha etkili olduğu vurgulanmıştır.

\section{PROPOLİS ENKAPSÜLASYONU}

Enkapsülasyon yönteminde taşıyıcı madde ve/veya maddeler, bileşen ile çevre arasında bir bariyer oluşturarak bileşenin 1s1, 1şık, oksijen ve metal iyonları gibi çevresel etmenlerden korunmasını sağlamaktadır (Tontul, 2011). Propolisin farklı taşıyıcı maddelerle enkapsülasyonu istenmeyen tat/aromasinın önlenmesinde, biyoaktif bileşenlerinin korunmasında, çözünürlüğ̈n̈ün ve biyoyararlllığının geliştirilmesinde, ucuz ve kararlı bileşenlerinin hazırlanmasında gida ve eczacilık gibi alanlarda alternatif bir yöntem olarak tercih edilmeye başlanmıştur (Keskin vd., 2018; Šturm vd., 2019). Subaş1-Zarbaliyev (2018), elektropüskürtme yöntemi kullanarak suda çözünebilir bir polimer olan polivinil alkol (PVA) içerisine propolis ekstraktını nano ölçekte enkapsüle ederek bu nanopartiküllerin \%80-89 aralığında DPPH radikal süpürücü aktivite gösterdiğini ve suda çözündügünü belirlemiştir. Propolis ekstraktının mikrokapsüllenmesinde taşıyıcı bileşen olarak en yaygın kullanılanlar; jelatin (Dota vd., 2011), maltodekstrin, arap zamk1-maltodekstrin (Busch vd., 2017) ve arap zamk1-maltodekstrin-inülin (Šturm vd., 2019) maddeleri ile bu maddelerin kombinasyonlandır. Jansen-Alves vd. (2019), farklı konsantrasyonlarda (\%2, 4 ve 6$)$ bezelye 
proteinleri kullanarak kapsülledikleri propolis ekstraktlarından (\%1.0, 2.5 ve 5.0); $\% 2$ bezelye proteini ve $\% 5$ propolis ekstrakt ile en yüksek kapsülleme verimi elde etmişlerdir. $\% 2$ protein ve $\% 2.5$ ile \%5 ekstraktn ise Listeria monocytogenes ve Staphylococcus aureus'a karşı antimikrobiyal aktivite gösterdiğini rapor etmişlerdir.

\section{PROPOLISIIN KULLANIM ŞEKLİ VE ALANLARI}

Propolisin kimyasal yapis1 ve biyoaktif özelliklerinden dolayı eczacılık, tıp, gida, veteriner hekimlik ve kozmetik gibi sektörlerde farkl1 şekillerde (ekstrakt, kapsül, toz, tablet, softjel ve damlalık gibi) ve çeşitli ürünlerde (gargara, diş macunu, losyon, sabun, pastil, sakız, şarap, kek, krem gibi) kullanımı yaygınlaşmıştır (Ferreira vd., 2017; Yumnam vd., 2017). Etanolik propolis ekstraktının, gargara ve diş macunlarında kullanımı sonucu diş ağrısını hafiflettiği, diş taşı oluşumunu ve diş eti iltihabını gidermeye yardımcı olduğu bildirilmiştir (Pasupuleti vd., 2017). Propolis, biyoaktif özelliklerinden dolayı cildin nemlendirilmesi, yenilenmesi ve kırışıklıkların giderilmesinde çeşitli krem ve losyon gibi kozmetik ürünlerde kullanılmaktadır. Hayvancılık sektöründe ise tavuk ve ördeklerde, propolis katk1lı yemlerin büyümeyi hızlandırdığı, vücut ağırlığını olumlu etkilediği ve yem verimliliğini artturdığ1 bildirilmiştir (Hašč́k vd., 2015).

\section{Gıda Alanında Kullanımı}

Propolisin son y1llarda takviye edici gida olarak kullanımının arttı̆ı gözlenmektedir (Çizelge 2). Pandemi süreci ile birlikte takviye edici gida şeklinde tüketilen propolis miktarında önemli artış olmuştur. Buna bağlı olarak önceleri arıcılar tarafinda kovanlardan toplanmayan ham propolislerin değerinin oldukça arttığ1 görülmektedir. Talepteki bu artışa bağlı olarak ham propolisin birim fiyatının 2.0-2.5 kat arttığ1 tespit edilmiştir. Zengin biyoaktif madde içeriğine bağlı olarak 20-50 mL'lik damlalıklı şişeler içerisinde piyasaya arz edilen propolis ekstraktları, herhangi bir siviya 8-10 damla damlatlarak doğrudan tüketilmektedir. Propolis ekstraktları doğrudan tüketimin yanında gıdalara eklenerek veya yüzeysel olarak propolis ekstraktlarına yiyeceklerin daldırılmasıyla kullanılmaktadır.
Ayrıca gıdalar, propolis ekstraktı içeren polimerlere dayanan özel olarak geliştirilmiş tabakalarla da kaplanmaktadır (Pobiega vd., 2019). Propolis, antioksidan ve antimikrobiyal aktivite göstererek kullanıldığı ürünün raf ömrünü artırmaktadır. Böylece gıdalardaki yapay koruyucular yerine kullanılabileceği ifade edilmektedir (Kunrath vd., 2017). Zahid vd. (2013), \%0.5'lik propolis etanolik ekstraktına daldırlan ejder meyvesinin depolanması sonucu meyvenin olgunlaşma sürecinin yavaşladığını, toplam flavonoidler ve antioksidanlar gibi gida bileşenlerinin biyosentezinin arttığını, daha yüksek konsantrasyonların (\%0.75 ve 1.0$)$ ise meyve yüzeyinde bazı fitotoksik etkiler gösterdiğini bildirmişlerdir. Silici ve Karaman (2014), elma suyuna ilave ettikleri propolis eksraktı $(0.1,1$ ve $2 \mathrm{mg} / \mathrm{mL}$ ) ile sodyum benzoat $(0.35 \mathrm{mg} / \mathrm{mL})$ arasindan, $2 \mathrm{mg} / \mathrm{mL}$ propolisin patulin üretimini önemli ölçüde azaltarak kimyasal koruyuculara alternatif doğal bir antifungal bileşen olabileceğini saptamışlardır. Safaei ve Azad (2020), farkl1 oranlarda (\%0, 10, 20 ve 40) propolis etanolik ekstraktı, propilen glikol ve $\mathrm{CaCO}_{3}$ içeren poli-laktik asit filmler ile kapladıkları sosislerden propolis eksrakt1 içerenlerin Staphylococcus aureus üzerinde antimikrobiyal etki gösterdiğini gözlemiştir. Pseudomonas aeruginosa üzerinde inhibe edici etki göstermesi için polietilen glikol/ $\mathrm{CaCO}_{3}$ içeriğine ihtiyaç duyduğunu bildirmiştir. Yapılan bazı çalışmalarda yoğurt içine farklı oranlarda $(\% 0.01,0.03,0.10$ ve 0.20$)$ propolis ekstraktı ilavesinin yoğurdun antioksidan aktivitesini artırdığ1 ve mikrobiyal gelişimini yavaşlattı̆̆ (Güney, 2016) ancak yoğurda \%0.5 oranında propolis ekstraktı ilavesinin Lactobacillus gelişiminine bir etkisinin olmadığ1 (Bilici, 2017) gözlenmiştir. Mehmetoğlu (2019) ise farklı oranlarda (\%0.1, $0.2,0.3,0.4$ ve 0.5$)$ propolis ekstraktı ilave ettiği dondurmanın fiziksel ve duyusal özelliklerinin bir miktar olumsuz etkilendiğini ancak propolisin üründe antioksidan aktivite gösterdiğini ifade etmiştir.

\section{PROPOLİSIN TERAPÖTİK ETKİLERİ İLE ÍLGİLI YAPILAN ÇALIŞMALAR}

Yapılan çeşitli çalışmalarda propolisin antioksidan (Osés vd., 2020), antibakteriyel (Khoshnevisan vd., 2019), antifungal (Ünal, 2019), 
antikanserojenik (Duran, 2019), antienflamatuvar (Aldemir ve Memmedov, 2019), antikaryojenik, antigingivitis ve yara iyileştirici (Sforcin, 2016) gibi aktiviteleri ortaya koyulmuştur. Propolisin biyolojik aktivitesinin, kovan çevresindeki iklim, coğrafi değişiklikler ve flora ile güçlü bir ilişkide olduğu belirlenmiştir (Özdal vd., 2019). Propolis örneklerinin antioksidan kapasitelerinin yapılarındaki gallokateşin, kateşin, epikateşin gallat, kafeik asit, kafeik asit feniletil ester (KAFE), klorojenik asit ve miristisin, galangin ve pinosembrin gibi fenolik bileşenlerden kaynaklandığ1 tespit edilmiştir (Özdal vd., 2019; Osés vd., 2020). Propolisin antifungal etkilerinden sorumlu olan bileşikler yapılan bazı çalışmalara göre başta pinosembrin olmak üzere galangin, kateşin, sinnamik asit, $\alpha$-pinen, $\beta$-pinen, $\delta$ - kadinen, fenil, etil ve benzil alkol olarak bildirilmiştir (Ioshida vd., 2010). Yapılan çalışmaların incelenmesiyle propoliste etkili olan kanser önleyici bileşenlerin; KAFE, krisin, artepilin C, nemoroson, galangin ve kardanol olduğu belirlenmiştir (Patel vd., 2016). Propolise antienflamatuvar etki kazandıran önemli fenolik bileşikler arasında; artepilin C, apigenin, kuersetin, pinosembrin, kaemferol, ferulik asit ve KAFE yer almaktadır (Martinotti ve Ranzato, 2015; Aldemir ve Memmedov, 2019). Yara, yantk ve cilt inflamasyonu gibi durumlarda dokunun onarım ve yenilenmesinde propolisin terapötik özelliği ve deriyi $\% 80$ düzeyinde iyileştirdiği bildirilmiştir. Bu etkinin propolisin içerisindeki fenolik bileşiklerden kaynaklandığı tespit edilmiştir (Sforcin, 2016).

Çizelge 2. Propolis kullanılan gıda ürünleri ve fonksiyonel etkileri

\begin{tabular}{|c|c|c|}
\hline Meyve-sebze ve ürünleri & Gıdadaki fonksiyonlanı & Kaynaklar \\
\hline $\begin{array}{l}\text { Muz, taze doğranmış karışık } \\
\text { sebzeler ve domates }\end{array}$ & $\begin{array}{l}\text { Antimikrobiyal va antioksidan } \\
\text { aktivite, ağırlık ve sağlamlık } \\
\text { kayıplarının azaltılması, raf ömrünü } \\
\text { artırma }\end{array}$ & $\begin{array}{l}\text { Passos vd. (2016); Alvarez vd. } \\
\text { (2017); Migliori vd. (2017) }\end{array}$ \\
\hline $\begin{array}{l}\text { Meyve suları (portakal, beyaz } \\
\text { üzüm, nar ve mandalina) }\end{array}$ & $\begin{array}{l}\text { Antimikrobiyal ve antioksidan } \\
\text { aktivite }\end{array}$ & $\begin{array}{l}\text { Kahramanoglu ve Usanmaz } \\
\text { (2017); Yang (2017) }\end{array}$ \\
\hline \multicolumn{3}{|l|}{ Süt-süt ürünleri ve yumurta } \\
\hline $\begin{array}{l}\text { Süt, yoğurt, } \\
\text { dondurma, yumurta }\end{array}$ & $\begin{array}{l}\text { Antimikrobiyal aktivite, kaliteyi } \\
\text { koruma, raf ömrünü artırma }\end{array}$ & $\begin{array}{l}\text { Güler (2016); Pedonese vd. } \\
\text { (2019); Santos vd. (2020) }\end{array}$ \\
\hline \multicolumn{3}{|l|}{ Et ve et ürünleri } \\
\hline $\begin{array}{l}\text { Tavukgöğsü, köfte, balık } \\
\text { burger }\end{array}$ & $\begin{array}{l}\text { Antimikrobiyal ve antioksidan } \\
\text { aktivite, kaliteyi koruma, raf ömrünü } \\
\text { artırma }\end{array}$ & $\begin{array}{l}\text { dos Reis } \\
\text { Mehdizadeh } \\
\begin{array}{l}\text { ve } \\
(2019)\end{array}\end{array}$ \\
\hline \multicolumn{3}{|l|}{ Tahıl ürünleri } \\
\hline Muffin & $\begin{array}{l}\begin{array}{l}\text { Antimikrobiyal ve antioksidan } \\
\text { aktivite }\end{array} \\
\end{array}$ & Bağdatlı (2019) \\
\hline \multicolumn{3}{|l|}{ Diğer ürünler } \\
\hline Sakız & $\begin{array}{l}\text { Antimikrobiyal aktivite, } \\
\text { sağlama }\end{array}$ & Bölük (2019) \\
\hline Puding & Fonksiyonel ürün & Aktaş (2019) \\
\hline Balık yağı & Antioksidan aktivite & Uçak (2018) \\
\hline
\end{tabular}




\section{PROPOLİS VE GIDA GÜVENLİĞİ}

Günümüzde Brezilya, ABD, AB (Avrupa Birliği), Avustralya, Kanada, Çin, Japonya ve Kore'de propolis kullanımına yönelik yasal düzenlemeler getirilmiştir (Berretta vd., 2017). AB'de propolis, "konsantre besin kaynaklar1/besin/fizyolojik etkiye sahip diğer maddeler" olarak bir grup tarafından 2002/46/EC sayılı yönergeye göre düzenlenmiş gida takviyesi olarak siniflandirilmaktadır (European Parliament and Council of the European Union, 2002). Şimdiye kadar EFSA, üretim alanina ve ekstraksiyon yöntemine bağl1 olarak, propolisin tüm özelliklerinin olmaması ve çeşitli propolis formülasyonlarının bileşimindeki farklılıklar nedeniyle gida ürün etiketlerine eklenecek sağltk beyanlarını yayınlayamamıştır (EFSA, 2010; Pobiega vd., 2019). Ülkemizde de piyasada bulunan ticari propolis preparasyonlarının çoğunun kimyasal yapısı ve günlük tüketim dozu hakkında bilgi yer almamaktadır (Silici, 2019). EFSA raporuna göre propolisin dahili kullanımı 0.7-1.3 g/gün ve güvenli kullanım sınırı 2 $\mathrm{g} / \mathrm{kg} /$ gün propolis olarak açılklanmıştır. Gıda takviyesi ile günlük doz alımı 24-72 mg propolis olarak bildirilmiştir ve $\% 0.5$ seyreltilmiş propolisin günde iki kez ağız spreyi olarak veya ağız çalkalamada kullanılması uygun görülmüştür. Propolis ekstraktının kullanımı günde 1 veya 3 kez çocuklar için en az $250 \mathrm{mg}$ /gün, yetişkinler için ise 750 mg/gündür (EFSA, 2010; EFSA, 2018). Araştırmalara göre propolisin vücutta oluşturduğu alerjik etkisi genel olarak kaşıntı, ciltte kızarıklık ve şişme, stomatitis (ağız yarası), perioral egzama ve nefes darlığ şeklinde bildirilmiştir (Shinmei vd., 2009; Cho vd., 2011). Genellikle bu reaksiyonlar daha çok propolisle doğrudan temasta bulunan arıcilarda, özellikle hassas bireylerde, propolisin fazla miktarda kullanıldığ1 durumlarda ve son zamanlarda da propolisle ilgili kozmetik ürün kullananlarda görülmektedir (Silici, 2015). Propoliste başlica alerjen bileşenler olarak kafeik asit esterleri (3,3-dimetilallil kafeat, 1,1dimetilallil kafeik asit, benzil kafeat ve geranil kafeat gibi) ve sinnamik asit esterleri (sinnamil sinnamat, benzil sinnamat ve sinnamil alkol gibi) belirlenmiştir (Basista-Sołtys, 2013).
Propolisteki toksik elementlerin (pestisitler, böcek öldürücüler, radyonüklidler, ağır metaller ve polisiklik aromatik hidrokarbonlar $(\mathrm{PAH})$ gibi) varlığ1 hava, su, bitki ve toprak gibi çeşitli kaynakların çevresel kirliliğine maruz kalmasıyla ilişkili bulunmuştur (González-Martín vd., 2018). Pestisit kalıntıları propoliste bulunabilen ve potansiyel olarak toksik diğer bileşikler arasında yer almaktadır. Genellikle tarımsal uygulamalardaki kontaminasyonlardan veya ar1 akarının (Varroa jacobsoni Qud.) önlenmesi için kovanlara pestisit uygulanmasindan kaynaklanmaktadır (Niell vd., 2015). Propolis bir ilaç olmayıp tubbi tedaviyi destekleyici olarak ancak hekim tavsiyesinde ve gözetiminde kullanılmalıdır (Yücel vd., 2014).

\section{SONUÇ}

Biyoaktif bileşen içeriğinin fazlalığı, doğal ürünler için artan tüketici talebi ve ana bileşenlerinin GRAS (Generally Recognized As Safe) olarak kabul edilmesi nedeniyle propolis, yiyecek ve içecek üretiminde antibakteriyel, antifungal ve antioksidatif özelliklere sahip doğal bir koruyucudur. Bunun yanı sıra gıdanın raf ömrünü uzatmak üzere fonksiyonel etkiler göstermektedir. Ancak endüstriyel açıdan değerlendirildiğinde, propolisin karakteristik tadı ve lezzeti ile değişken kimyasal bileşimi gıdalarda kullanımını kısıtlayan nedenler arasındadır. Sonuç olarak propolis; toksik olmayan, genel anlamda güvenilir ve ilaç olarak kabul edilmeyen bir ürün olarak tanımlanabilir. Tibbi tedaviyi destekleyici olarak ancak hekim tavsiyesiyle kullanilması uygundur. Propolis bileşiminin, olası uygulamaları geliştirme ve yeni buluşlara yol açma potansiyeli öngörülerek üzerinde daha fazla araştırmaya ihtiyaç duyulmaktadır.

\section{ÇIKAR ÇATIŞMASI BEYANI}

Yazarlar, bu makale ile ilgili başka kişi veya kurumlar ile çıkar çatışması olmadığını beyan eder.

\section{YAZAR KATKILARI}

Tüm yazarlar makalenin yapilmasinda, yazılmasında ve yayınlanmasında eşit katkı sağlamışlardır. 


\section{KAYNAKÇA}

Aktaş, A. (2019). Enkapsüle edilmiş propolis ekstraktının muz aromalı puding üretiminde kullanımı. Sivas Cumhuriyet Üniversitesi Fen Bilimleri Enstitüsü Gıda Mühendisliği Anabilim Dalı Yüksek Lisans Tezi, Sivas, Türkiye, 43 s.

Aldemir, O., Memmedov, H. (2019). Propolisin bileşenlerinden olan kafeik asit fenil esterin antienflamatuvar etkileri. Arcollk Arastırma Dergisi, 11(2): 43-47.

Alvarez, M.V., Ponce, A.G., Goyeneche, R., Moreira, M.R. (2017). Physical treatments and propolis extract to enhance quality attributes of fresh-cut mixed vegetables. J Food Process Preserv, 41(5):

https://doi.org/10.1111/jfpp.13127.

e13127,

Bağdatlı, M. (2019). Enkapsüle propolisin fonksiyonel gida üretiminde kullanılması. İnönü Üniversitesi Fen Bilimleri Enstitüsü Gıda Mühendisliği Anabilim Dalı Yüksek Lisans Tezi, Malatya, Türkiye, 66 s.

Basista-Sołtys, K. (2013). Allergy to propolis in beekeepers-A literature review. Occup Med Health Aff, 1: 1-3, http://dx.doi.org/10.4172/23296879.1000105.

Baysa, M. (2018). Propolisin antipiretik etkisinin belirlenmesi. Erciyes Üniversitesi Fen Bilimleri Enstitüsü Tarımsal Biyoteknoloji Anabilim Dalı Yüksek Lisans Tezi, Kayseri, Türkiye, 30 s.

Berretta, A.A., Arruda, C., Miguel, F.G., Baptista, N., Nascimento, A.P., Marquele-Oliveira, F., Hori, J.I., da Silva Barud, H., Damaso, B., Ramos, C., Ferreira, R., Bastos, J.K. (2017). Functional properties of Brazilian propolis: From chemical composition until the market. Superfood and functional food: An overview of their processing and utilization, Waisundara, V., Shiomi, N. (ed), IntechOpen, Rijeka, Croatia, pp. 55-98.

Bilici, C. (2017). Lepidium meyenii tozu ve propolis ekstraktı ilave edilerek fonksiyonel özellikleri geliştirilmiş yoğurt üretilmesi. Marmara Üniversitesi Sağlık Bilimleri Enstitüsü Beslenme ve Diyetetik Anabilim Dalı Yüksek Lisans Tezi, İstanbul, Türkiye, 42-43 s.
Bölük, E. (2019). Şekerli ve şekersiz propolisli sakız üretim optimizasyonu. Tekirdağ Namık Kemal Üniversitesi Fen Bilimleri Enstitüsü Gıda Mühendisliği Anabilim Dalı Yüksek Lisans Tezi, Tekirdağ, Türkiye, $49 \mathrm{~s}$.

Busch, V.M., Pereyra-Gonzalez, A., Šegatin, N., Santagapita, P.R., Ulrih, N.P., Buera, M.P. (2017). Propolis encapsulation by spray drying: Characterization and stability. LWT-Food Sci Technol, 75: 227-235, https://doi.org/10.1016/j.lwt.2016.08.055.

Chemat, F., Rombaut, N., Sicaire, A.G., Meullemiestre, A., Fabiano-Tixier, A.S., AbertVian, M. (2017). Ultrasound assisted extraction of food and natural products. Mechanisms, techniques, combinations, protocols and applications. A review. Ultrason Sonochem, 34: 540560 ,

http://dx.doi.org/10.1016/j.ultsonch.2016.06.03 5.

Cho, E., Lee, J.D., Cho, S.H. (2011). Systemic contact dermatitis from propolis ingestion. Ann Dermatol, 23(1): 85-88, doi:10.5021/ad.2011.23.1.85.

Devequi-Nunes, D., Machado, B.A.S., Barreto, G.D.A., Rebouças Silva, J., da Silva, D.F., da Rocha, J.L.C., Brandão, H.N., Borges, V.M., Umsza-Guez, M.A. (2018). Chemical characterization and biological activity of six different extracts of propolis through conventional methods and supercritical extraction. PLoS One, 13(12): e0207676, https://doi.org/10.1371/journal.pone.0207676.

Dhanani, T., Shah, S., Gajbhiye, N.A., Kumar, S. (2017). Effect of extraction methods on yield, phytochemical constituents and antioxidant activity of Withania somnifera. Arab J Chem, 10: 1193-1199, https://doi.org/10.1016/j.arabjc. 2013.02.015.

dos Reis, A.S., Diedrich, C., de Moura, C., Pereira, D., de Flório Almeida, J., da Silva, L.D., Oviedo, M.S. V.P., Tavares, R.A.W., Carpes, S.T. (2017). Physico-chemical characteristics of microencapsulated propolis co-product extract and its effect on storage stability of burger meat during storageat $-15{ }^{\circ} \mathrm{C}$. LWT-Food Sci Technol, 
76: 306-313, https://doi.org/10.1016/j.lwt. 2016.05.033.

Dota, K.F.D., Consolaro, M.E.L., Svidzinski, T. I.E., Bruschi, M.L. (2011). Antifungal activity of Brazilian propolis microparticles against yeasts isolated from vulvovaginal candidiasis. Evid Based Complement Alternat Med, 2011, https://doi.org/10.1093/ecam/neq029.

Duran, G.G. (2019). A549 kanser hücre hattında propolisin antikanserojen etkinliğinin araşturlması. Hatay Mustafa Kemal Üniversitesi Sağllk Bilimleri Enstitüsü Moleküler Biyokimya ve Genetik Anabilim Dalı Yüksek Lisans Tezi, Hatay, Türkiye, 52 s.

Dündar, E. (2019). Propolisteki fenolik bileşiklerin farklı biyotransformasyon koşullarındaki değişimi. Ege Üniversitesi Fen Bilimleri Enstitüsü Gıda Mühendisliği Anabilim Dalı Yüksek Lisans Tezi, İzmir, Türkiye, $91 \mathrm{~s}$.

Ecem-Bayram, N., Sorkun K., Cevahir-Öz, G., Salih, B., Topçu, G. (2018). Chemical characterization of 64 propolis samples from Hakkari, Turkey. Rec Nat Prod, 12(6): 569-581, https://doi.org/10.25135/rnp.78.16.12.585.

European Parliament and Council of the European Union (2002). Directive 2002/46/EC on the approximation of the laws of the member states relating to food supplements. $O J, 183$ : 5157.

EFSA Panel on Dietetic Products, Nutrition and Allergies (NDA) (2010). Scientific Opinion on the substantiation of health claims related to propolis (ID 1242, 1245, 1246, 1247, 1248, 3184) and flavonoids in propolis (ID 1244, 1644, 1645, $3526,3527,3798,3799)$ pursuant to article 13(1) of regulation (EC) No 1924/2006. EFS A J, 8(10): 1810, https://doi.org/10.2903/j.efsa.2010.1810.

European Food Safety Authority (EFSA) (2018). Outcome of the consultation with member states and EFSA on the basic substance application for propolis extract (admissibility accepted when named water-soluble extract of propolis) for use in plant protection as fungicide and bactericide. EFSA Support Publ, 15(11): 1494E, https://doi.org/10.2903/sp.efsa.2018.EN-1494.
Elnakady, Y.A., Rushdi, A.I., Franke, R., Abutaha, N., Ebaid, H., Baabbad, M., Omar, M. O., Al Ghamdi, A.A. (2017). Characteristics, chemical compositions and biological activities of propolis from Al-Bahah. Saudi Arabia Sci Rep, 7: 41453, doi: 10.1038/srep41453.

Ferreira, J.M., Fernandes-Silva, C.C., Salatino, A., Negri, G., Message, D. (2017). New propolis type from north-east Brazil: Chemical composition, antioxidant activity and botanical origin. J Sci Food Agric, 97(11): 3552-3558, https://doi.org/ $10.1002 /$ jsfa. 8210 .

Fitzgerald, K.F., Flood, A.A. (2006). Hymenoptera stings. Clin Tech Small Anim Pract, 21: 194-204, https://doi.org/10.1053/ j.ctsap.2006.10.002.

Funari, C.S., Sutton, A.T., Carneiro, R.L., Fraige, K., Cavalheiro, A.J., da Silva Bolzani, V., Hilder, E.F., Arrua, R.D. (2019). Natural deep eutectic solvents and aqueous solutions as an alternative extraction media for propolis. Food Res Int, 125: 108559,

https://doi.org/10.1016/j.foodres.2019.108559.

Gardana, C., Barbieri, A., Simonetti, P., Guglielmetti, S. (2012). Biotransformation strategy to reduce allergens in propolis. Appl Environ Microbiol, 78(13): 4654-4658, doi: 10.1128/AEM.00811-12.

González-Martin, M.I., Revilla, I., BetancesSalcedo, E.V., Vivar-Quintana, A.M. (2018). Pesticide residues and heavy metals in commercially processed propolis. Microchem J, 143: 423-429, https://doi.org/10.1016/ j.microc.2018.08.040.

Güler, G. (2016). Serbest olarak yetiştirilen yumurta tavuklarinın yemlerinde ve yumurtalarında propolis ekstraktı kullanımının raf ömrü ve kalite parametrelerine etkileri. Namık Kemal Üniversitesi Fen Bilimleri Enstitüsü Zootekni Anabilim Dalı Yüksek Lisans Tezi, Tekirdağ, Türkiye, 59 s.

Güney, F. (2016). Bazı propolis özütlerinin meyveli yoğurtların biyokimyasal, fizikokimyasal ve raf ömrü üzerine etkilerinin araştırılması. Ordu Üniversitesi Fen Bilimleri Enstitüsü Biyoloji 
Anabilim Dalı Yüksek Lisans Tezi, Ordu, Türkiye, $55 \mathrm{~s}$.

Haščík, P., Elimam, I.O., Kročko, M., Bobko, M., Kačániová, M., Garlík, J., Šimko, M., Saleh, A.A. (2015). The influence of propolis as supplement diet on broiler meat growth performance, carcass body weight, chemical composition and lipid oxidation stability. Acta Univ Agric Silvic Mendel Brun, 63(2): 411-418, http://dx.doi.org/10.11118/actaun20156302041 1.

Hegazy, M.E.F., Mohamed, T.A., ElShamy, A.I., Abou-El-Hamd, H.M., Mahalel, U.A., Reda, E.H., Shaheen, A.M., Tawfik, W.A., Shahat, A.A., Shams, K.A., Abdel-Azim, N.S. (2015). Microbial biotransformation as a tool for drug development based on natural products from mevalonic acid pathway: A review. J Adv Res, 6(1): 17-33, https://doi.org/10.1016/j.jare.2014.11.009.

Ioshida, M.D.M., Young, M.C.M., Lago, J.H.G. (2010). Chemical composition and antifungal activity of essential oil from Brazilian propolis. $J$ Essent Oil Bear Pl, 13: 633-637, https://doi.org/10.1080/0972060X.2010.10643 873.

Jansen-Alves, C., Maia, D.S., Krumreich, F.D., Crizel-Cardoso, M.M., Fioravante, J.B., da Silva, W.P., Borges, C.D., Zambiazi, R.C. (2019). Propolis microparticles produced with pea protein: Characterization and evaluation of antioxidant and antimicrobial activities. Food Hydrocoll, 87: 703-711, https://doi.org/10.1016/j.foodhyd.2018.09.004.

Kahramanoglu, I., Usanmaz, S. (2017). Effects of propolis and black seed oil on the shelf life of freshly squeezed pomegranate juice. Food Sci Nutr, 1(2): 114-121, doi:10.22158/ fsns.v1n2p114.

Kayabaşı, S. (2019). Yeni nesil teknikler kullanılarak hazırlanan propolis ekstraktlarının fitokimyasal özelliklerinin ve antioksidan kapasitelerinin karşılaştırılması. Bayburt Üniversitesi Lisansüstü Eğitim Enstitüsü Gıda Mühendisliği Anabilim Dalı Yüksek Lisans Tezi, Bayburt, Türkiye, $45 \mathrm{~s}$.
Keskin, S., Keskin, M., Kolayli, S. (2018). A new approach to propolis extraction. J Apither Nat, 1(3): 26-26.

Keskin, M., Keskin, S., Kolayli, S. (2019). Preparation of alcohol free propolis-alginate microcapsules, characterization and release property. LWT-Food Sci Technol, 108: 89-96, https://doi.org/10.1016/j.lwt.2019.03.036.

Khoshnevisan, K., Maleki, H., Samadian, H., Doostan, M., Khorramizadeh, M.R. (2019). Antibacterial and antioxidant assessment of cellulose acetate/polycaprolactone nanofibrous mats impregnated with propolis. Int $J$ Biol Macromol, $\quad 140:$ 1260-1268, https://doi.org/10.1016/j.ijbiomac.2019.08.207.

Kunrath, C.A., Savoldi, D.C., Mileski, J.P.F., Novello, C.R., Alfaro, A.D.T., Marchi, J.F., Tonial, I.B. (2017). Application and evaluation of propolis, the natural antioxidant in Italian-type salami. Braz J Food Technol, 20: 1-10, https://doi.org/10.1590/1981-6723.3516.

Liu, Y., Friesen, J.B., McAlpine, J.B., Lankin, D.C., Chen, S.N., Pauli, G.F. (2018). Natural deep eutectic solvents: Properties, applications, and perspectives.J Nat Prod,81(3): 679-690, https://doi.org/10.1021/acs.jnatprod.7b00945.

Martinotti, S., Ranzato, E. (2015). Propolis: A new frontier for wound healing?. Burns Trauma, 3(1): 9, https://doi.org/10.1186/s41038-015-0010-z.

Mehdizadeh, T., Langroodi, A.M. (2019). Chitosan coatings incorporated with propolis extract and Zataria multiflora Boiss oil for active packaging of chicken breast meat. Int J Biol Macromol, $\quad 141$ : 401-409, https://doi.org/10.1016/j.ijbiomac.2019.08.267.

Mehmetoğlu, S. (2019). Propolis katk1lı dondurmaların depolama süresince fizikokimyasal yapısının incelenmesi. Ordu Üniversitesi Fen Bilimleri Enstitüsü Gıda Mühendisliği Anabilim Dalı Yüksek Lisans Tezi, Ordu, Türkiye, 52 s.

Mello, B.C.B.S., Petrus, J.C.C., Hubinger, M.D. (2010). Concentration of flavonoids and phenolic compounds in aqueous and ethanolic propolis extracts through nanofiltration. J Food Eng, 96: 
533-539, https://doi.org/10.1016/j.jfoodeng. 2009.08.040.

Migliori, C.A., Salvati, L., Di Cesare, L.F., Scalzo, R.L., Parisi, M. (2017). Effects of preharvest applications of natural antimicrobial products on tomato fruit decay and quality during long-term storage. Sci Hortic, 222: 193-202, https://doi.org/10.1016/j.scienta.2017.04.030.

Niell, S., Jesus, F., Perez, C., Mendoza, Y., Diaz, R., Franco, J., Cesio, V., Heinzen, H. (2015). QuEChERS adaptability for the analysis of pesticide residues in beehive products seeking the development of an agroecosystem sustainability monitor. J Agric Food Chem, 63(18): 4484-4492, https://doi.org/10.1021/acs.jafc.5b00795.

Oroian, M., Dranca, F., Ursachi, F. (2020). Comparative evaluation of maceration, microwave and ultrasonic-assisted extraction of phenolic compounds from propolis. J Food Sci Technol, 57(1): 70-78, https://doi.org/10.1007/s13197-019-04031-x.

Osés, S.M., Marcos, P., Azofra, P., de Pablo, A., Fernández-Muíño, M.Á., Sancho, M.T. (2020). Phenolic profile, antioxidant capacities and enzymatic inhibitory activities of propolis from different geographical areas: Needs for analytical harmonization. Antioxidants, 9(1): 75, https://doi.org/10.3390/antiox9010075.

Özdal, T., Ceylan, F.D., Eroğlu, N., Kaplan, M., Olgun, E.O., Capanoglu, E. (2019). Investigation of antioxidant capacity, bioaccessibility and LCMS/MS phenolic profile of Turkish propolis. Food Res Int, 122: 528-536, https://doi.org/10.1016/j.foodres.2019.05.028.

Passos, F.R., Mendes, F.Q., Cunha, M.C., Pigozzi, M.T., Carvalho, A.M.X.D. (2016). Propolis extraction in postharvest conservation banana 'Prata'. Rev Bras Frutic, 38(2): e-931, http://dx.doi.org/10.1590/0100-29452016931.

Pasupuleti, V.R., Sammugam, L., Ramesh, N., Gan, S.H. (2017). Honey, propolis, and royal jelly: A comprehensive review of their biological actions and health benefits. Oxid Med Cell Longev, 2017, https://doi.org/10.1155/2017/1259510.
Patel, S. (2016). Emerging adjuvant therapy for cancer: Propolis and its constituents. J Diet Suppl, 13(3): 245-268, https://doi.org/10.3109/ 19390211.2015.1008614.

Pedonese, F., Verani, G., Torracca, B., Turchi, B., Felicioli, A., Nuvoloni, R. (2019). Effect of an Italian propolis on the growth of Listeria monocytogenes, Staphylococcus aureus and Bacillus cereus in milk and whey cheese. Ital J Food Saf, 8(4): 8036, doi: $10.4081 /$ ijfs.2019.8036.

Pobiega, K., Kraśniewska, K., Gniewosz, M. (2019). Application of propolis in antimicrobial and antioxidative protection of food quality-A review. Trends Food Sci Technol, 83: 53-62, https://doi.org/10.1016/j.tifs.2018.11.007.

Reis, J.H.D.O., Barreto, G.D.A., Cerqueira, J.C., Anjos, J.P.D., Andrade, L.N., Padilha, F.F., Druzian, J.I., Machado, B.A.S. (2019). Evaluation of the antioxidant profile and cytotoxic activity of red propolis extracts from different regions of northeastern Brazil obtained by conventional and ultrasound-assisted extraction. PLoS One, 14(7): e0219063, https://doi.org/10.1371/journal.pone.0219063.

Righi, A.A., Negri, G., Salatino, A. (2013). Comparative chemistry of propolis from eight Brazilian localities. Evid Based Complement Alternat Med, 2013, https://doi.org/10.1155/2013/267878.

Rodriguez-Jasso, R.M., Mussatto, S.I., Pastrana, L., Aguilar, C.N., Teixeira, J.A. (2011). Microwave-assisted extraction of sulfated polysaccharides (fucoidan) from brown seaweed. Carbohydr Polym, 86(3): 1137-1144, https://doi.org/10.1016/j.carbpol.2011.06.006.

Trusheva, B., Petkov, H., Popova, M., Dimitrova, L., Zaharieva, M., Tsvetkova, I., Najdenski, H., Bankova, V. (2019). "Green" approach to propolis extraction: Natural deep eutectic solvents. C R Acad Bulg Sci, 72(7): 897-905, doi: 10.7546/CRABS.2019.07.06.

Uçak, İ. (2018). Propolis ekstraktı ile zenginleştirilmiş balık yağında lipit oksidasyonu düzeyinin belirlenmesi. Grda, 43(3): 523-532, doi: 10.15237/gida.GD18031. 
Safaei, M., Azad, R.R. (2020). Preparation and characterization of poly-lactic acid based films containing propolis ethanolic extract to be used in dry meat sausage packaging. J Food Sci Technol, 57(4): 1242-1250, https://doi.org/10.1007/s13197-019-04156-z.

Santos, M.S., Estevinho, L.M., de Carvalho, C.A.L., da Silva Conceição, A.L., de Castro Almeida, R.C. (2020). Rheological and sensorial evaluation of yogurt incorporated with red propolis. J Food Sci Technol, 57(3): 1080-1089, https://doi.org/10.1007/s13197-019-04142-5.

Sforcin, J.M. (2016). Biological properties and therapeutic applications of propolis. Phytother Res, 30(6):

894-905, https://doi.org/10.1002/ptr.5605.

Sharaf, S., El-Naggar, M.E. (2018). Eco-friendly technology for preparation, characterization and promotion of honey bee propolis extract loaded cellulose acetate nanofibers in medical domains. Cellulose, 25: 5195-5204, https://doi.org/10.1007/s10570-018-1921-1.

Shinmei, Y., Yano, H., Kagawa, Y., Izawa, K., Akagi, M., Inoue, T., Kamei, C. (2009). Effect of Brazilian propolis on sneezing and nasal rubbing in experimental allergic rhinitis of mice. Immunopharmacol Immunotoxicol, 31(4): 688-693, https://doi.org/10.3109/08923970903078443.

Silici, S. (2015). Sağlkklı yaşamada propolisin yeri. Ar1 Ürünleri ve Sağlık (Apiterapi), Akçiçek, E., Yücel, B. (ed.), 1. Bask1, Sida Medya, İzmir, Türkiye, s. 125.

Silici, S., Karaman, K. (2014). Inhibitory effect of propolis on patulin production of Penicillium expansum in apple juice. J Food Process Preserv, 38(3): 1129-1134,https://doi.org/10.1111/jfpp.12072.

Silici, S. (2019). Honeybee products and apitherapy. Turk J Agric Food Sci Technol, 7(9): 1249-1262,

https://doi.org/10.24925/turjaf.v7i9.1249-

1262.2141.

Šturm, L., Črnivec, I.G.O., Istenič, K., Ota, A., Megušar, P., Slukan, A., Humar, M., Levic, S., Nedović, V., Kopinč, R., Deželak, M., Gonzales, A.P., Ulrih, N.P. (2019). Encapsulation of non- dewaxed propolis by freeze-drying and spraydrying using gum arabic, maltodextrin and inulin as coating materials. Food Bioprod Process, 116: 196211, https://doi.org/10.1016/j.fbp.2019.05.008.

Subaşı-Zarbaliyev, B. (2018). Elektropüskürtme yöntemiyle propolis yüklenmiş polivinil alkol nanopartiküllerinin üretimi ve karakterizasyonu. Yıldız Teknik Üniversitesi FenBilimleri Enstitüsü Gıda Mühendisliği Bilim Dalı Yüksek Lisans Tezi, İstanbul, Türkiye, 45-48 s.

Tontul, İ. (2011). Keten tohumu yağının püskürterek kurutmayla mikroenkapsülasyonu üzerine farklı taşıyıcı madde ve emülsiyon uygulamalarının etkilerinin araştırılması. Akdeniz Üniversitesi Fen Bilimleri Enstitüsü G1da Mühendisliği Anabilim Dalı Yüksek Lisans Tezi, Antalya, Türkiye, $1 \mathrm{~s}$.

Toreti, V.C., Sato, H.H., Pastore, G.M., Park, Y.K. (2013). Recent progress of propolis for its biological and chemical compositions and its botanical origin. Evid Based Complement Alternat Med, 2013: 1 13,https://doi.org/10.1155/2013/697390.

Tüzün, A., Bilgili, G. (2013). Tarımsal ekosistemde arrların önemi. Res J Biol Sci, 6(2): 91 95.

Ünal, Z.Ö. (2019). Trichophyton türleri üzerine propolis ve kurkumin ekstraktlarının antifungal aktivitesinin ve sinerjik etkisinin araşturlması. Namık Kemal Üniversitesi Sağlık Bilimleri Enstitüsü Tibbi Mikrobiyoloji Anabilim Dalı Yüksek Lisans Tezi, Tekirdağ, Türkiye, $81 \mathrm{~s}$.

Wang, T., Liu, Q., Wang, M., Zhang, L. (2020). Metabolomics reveals discrimination of Chinese propolis from different climatic regions. Foods, 9(4): 491 , https://doi.org/10.3390/foods9040491.

Yang, W., Wu, Z., Huang, Z, Y., Miao, X. (2017). Preservation of orange juice using propolis. J Food Sci Technol, 54(11): 1-9.

Yeo, K.L., Leo, C.P., Chan, D.J.C. (2015). Ultrasonic enhancement on propolis extraction at varied $\mathrm{pH}$ and alcohol content. J Food Process Eng, 38(6): 562-570, https://doi.org/10.1111/jfpe.12186. 
Yıldırım, H.K., Canbay, E., Öztürk, Ş., Aldemir, O., Sözmen, E.Y. (2018). Biotransformation of propolis phenols by L. plantarum as a strategy for reduction of allergens. Food Sci Biotechnol, 27(6): 1727-1733, https://doi.org/10.1007/s10068018-0413-2.

Yumnam, R., Nandan, N., Kumar, N.C., Raj, S., Mannepalli, A. (2017). Effect of propolis in oral health. J Ayurveda Integr Med, 2(1): 186-192, http://dx.doi.org/10.21760/jaims.v2i1.7509.

Yücel, B., Topal, E., Akçiçek, E., Kösoğlu, M. (2014). Propolisin insan sağllğına etkileri. Anadolu, 24: 41-49.
Zahid, N., Ali, A., Siddiqui, Y., MaqbooL, M. (2013). Efficacy of ethanolic extract of propolis in maintaining postharvest quality of dragon fruit during storage. Postharvest Biol Technol, 79: 69-72, https://doi.org/10.1016/j.postharvbio.2013.01.0 03.

Zhang, H., Fu, Y., Niu, F., Li, Z., Ba, C., Jin, B., Chen, G., Li, X. (2018). Enhanced antioxidant activity and in vitro release of propolis by acidinduced aggregation using heat-denatured zein and carboxymethyl chitosan. Food Hydrocoll, 81: 104-112,

https://doi.org/10.1016/j.foodhyd.2018.02.019. 